Article

\title{
Evaluation of the Effects of Forest on Slope Stability and Its Implications for Forest Management: A Case Study of Bailong River Basin, China
}

\author{
Siyuan Wang ${ }^{1}$, Minmin Zhao ${ }^{1, *}$, Xingmin Meng ${ }^{2}$, Guan Chen ${ }^{2}$, Runqiang Zeng ${ }^{2}$, Qiang Yang ${ }^{1}$, \\ Yi Liu ${ }^{1}$ and Biao Wang ${ }^{3}$ \\ 1 Center for Hydrogeology and Environmental Geology Survey, CGS, Baoding 071051, China; \\ wangsiyuan@mail.cgs.gov.cn (S.W.); yang5359535@126.com (Q.Y.); liuyi51861@163.com (Y.L.) \\ 2 Gansu Environmental Geology and Geohazards Research Centre, College of Earth and Environmental \\ Sciences, Lanzhou University, Lanzhou 100101, China; xmmeng@lzu.edu.cn (X.M.); \\ gchen@lzu.edu.cn (G.C.); zengrq@lzu.edu.cn (R.Z.) \\ 3 Beijing Institute of Water, Beijing 100048, China; wangbiao0312@163.com \\ * Correspondence: zhaominmin@163.com; Tel.: +86-0150-0250-2034
}

Received: 29 June 2020; Accepted: 7 August 2020; Published: 18 August 2020

\begin{abstract}
Previous studies have shown that the mechanical effects of vegetation roots on slope stability can be classified as additional cohesion effects and anchorage effects. The present study investigated the combined mechanical effects (additional cohesion effects and anchorage effects) of vegetation on a slope with coarse-grained soil in the mountainous region (significantly prone to slope failure) of Gansu Province, China. A detailed survey of tree density, root system morphology and slope profiles was conducted, and we also assessed the soil cohesion provided by the root systems of monospecific stands of Robinia pseudoacacia growing in different locations on the slope. The measured data were incorporated into a numerical slope model to calculate the stability of the slope under the influence of trees. The results indicated that it was necessary to consider the anchoring effect of coarse roots when estimating the mechanical effects of trees on slope stability. In particular, the FoS (factor of safety) of the slope was increased by the presence of trees. The results also demonstrated that vegetation increased slope stability. The reinforcing effects were most significant when the trees were planted along the entire slope. Although the reinforcing effects contributed by trees were limited (only 4-11\%), they were essential for making optimal use of vegetation for enhancing slope stability. Overall, vegetation development can make a major contribution to ecosystem restoration in the study region.
\end{abstract}

Keywords: Robinia pseudoacacia; anchorage effect; planted location; slope stability; forest management

\section{Introduction}

Research has demonstrated that the presence of woody plants can significantly restrict the development of shallow landslides [1-6]. This phenomenon has attracted increasing attention, and many attempts have been made to develop tests and analytical models of soil reinforcement mechanisms [7-10]. Mass movements on the eastern boundary of the Qinghai-Tibet Plateau are of particular interest since there are questions regarding the effectiveness of densely planted trees in limiting the occurrence of shallow landslides in mountainous regions. In addition, the aim of current soil and water conservation afforestation practices is to increase the survival rate of trees and to increase vegetation coverage. The requirements for afforestation can be summarized in terms of assessing site conditions, selecting the appropriate tree species and planting them at a specific density along the slope contours [11]. Thus, assessing the ability of tree roots to reinforce slopes is not only 
very important for increasing slope stability but also for improving the afforestation methodology in similar regions. Besides, studies have shown that plants like Robinia pseudoacacia could not only live in harsh environments but also significantly changed the vegetation flora, soil properties and microbial communities in cooperation with mycorrhizal fungi, which could benefit local ecosystems obviously in mountainous areas [12-14].

The use of vegetation to resist soil erosion and shallow landslides largely depends on the positive mechanical and hydrological effects of roots [15]. From a mechanical perspective, the influence of plant roots on slope stability operates mainly by reinforcing the soil and anchoring the surface soil. The two effects can substantially change the mechanical properties of the topsoil [16]. The presence of fine roots results in an increase in soil cohesion through the mechanical resistance of roots and root friction with soil particles. Most previous studies focused on the reinforcing effect, and several methods have been adopted to determine it. A root reinforcement mechanistic model was developed based on the assumption that all roots are fully broken in a state of tension and break simultaneously (named the WM, a model proposed by Wu et al.) [17,18]. As the WM always overestimates the actual soil-root strength, a correction factor was introduced in a modified version [19], which has been shown to provide accurate estimates of soil shear strength when reinforced by roots [18].

Anchorage is a widely used concept in geotechnical engineering. Most natural soils have relatively high shear strength and compressive strength, while the tensile strength is almost zero, so cracks caused by pulling are one of the main causes of soil failure [20]. Coarse root branches have developed within the deep soil layer, which significantly increases slope stability. Therefore, there are substantial limitations in applying current research methods in the study area of the eastern Qinghai-Tibet Plateau since they cannot fully reflect the influence of the root system of the principal species, Robinia pseudoacacia, on slope stability. The anchoring effects of trees operate via their maintaining an upright position and preventing the structure from failing or their being uprooted under the stresses of gravity, air or water flows [21]. Many studies have attempted to describe the anchoring effect of trees. Numerical methods, such as finite-element models, have been developed to simulate the root anchorage components and their behavior during tree overturning [22,23]; in addition, experiments involving pulling the trees out have been used to assess their actual anchoring ability [24-26].

In our study, the mechanical reinforcement effect of trees on the stability of a coarse-grained soil slope in Gansu Province, China, was estimated. The main aims of the study were (i) to describe the distribution of tree roots in a typical forested slope, (ii) to numerically analyze the mechanical impact of both fine and coarse roots on slope stability and (iii) to determine the influence of the planting location on the impact of slope reinforcement against shallow landslides. The profile method (for roots with diameters $<10 \mathrm{~mm}$, with the data recorded as the root area ratio (RAR) [27]) and the excavation method (for roots with diameters $>10 \mathrm{~mm}$ ) were combined to investigate the characteristics of the root system. Both the reinforcing and anchoring effects were integrated into a simple 2D limit equilibrium model of slope stability, which was used to analyze the effects of root variability and finite slope morphology on the factor of safety (FoS). It was hoped that our findings would contribute to forest management in similar regions.

\section{Materials and Methods}

\subsection{Vegetation and Site Characteristics}

The Bailong River Basin is well-known for its widely distributed and frequent geohazards and is listed as one of the four major areas in China prone to geohazards. The Goulinping Valley is a representative valley in the area, and the catchment geomorphology consists of high mountains with deep narrow valleys, with a relative elevation of $1950 \mathrm{~m}$ (Figure 1). A typical slope, mainly consisting of phyllite debris, was selected for study; the elevation was $1310 \mathrm{~m}$, the aspect was $45^{\circ}$ and the slope angle was $39^{\circ}$. Due to its relatively remote location and the absence of cultivation in the area, it is largely unaffected by human activities such as irrigation. 
Currently, the main vegetation on the valley floor consists of herbaceous plants (e.g., Potentilla aiscolor Bunge, Phragmites australis and Digitaria sanguinalis) and shrubs (e.g., Lespedeza bicolor, Coriaria nepalensis, Ziziphus jujuba and Amorpha fruticosa). The trees are mainly planted and include Robinia pseudoacacia (black locust) and Populus tomentosa (Chinese white poplar) [14]. Our investigation of the common herbaceous plants in the study area revealed that their root systems were mainly distributed in the upper part of the soil profile (usually less than $0.3 \mathrm{~m}$ in depth). Due to the lack of xylem, the cover density of herbaceous plants was significantly lower than that of woody plants. In addition, herbaceous plants generally have a short life span (mostly annual or biennial), and thus, they do not develop extensive and robust aboveground and underground parts. Thus, woody plants are more effective in reinforcing the soil and controlling soil erosion [28]. A previous survey revealed that the three commonly planted woody species (Robinia pseudoacacia, Amorpha fruticosa and Populus tomentosa) were well-adapted to the valley floor habitat [14], but only Robinia pseudoacacia grew well on the steep slopes and reproduced successfully. As a result, in the present research, Robinia pseudoacacia was selected as the key species in the region and was studied in detail. Six standard tree stands in the experimental area were selected, and the distribution characteristics of each plant root system were studied.

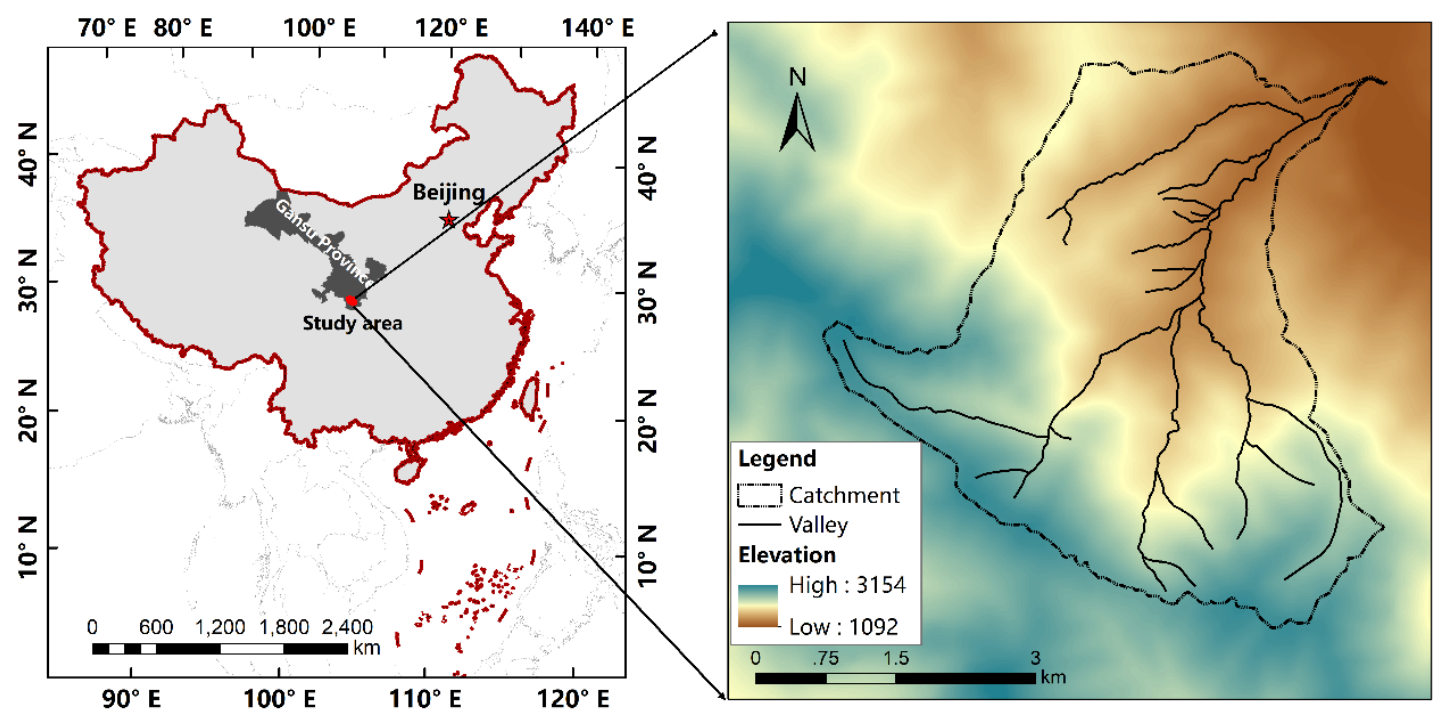

Figure 1. Location of the study area in China (left) and topography of the study watershed (right).

\subsection{Field Investigation of Root Systems}

In order to quantitatively describe the effects of trees on slope stability, several important parameters of trees and roots should be considered: tree distribution on the slope, root system architecture and the effect of root tensile strength on improving slope stability [3,29-31]. The root distribution of Robinia pseudoacacia on the slope was investigated using the section window method $[14,32]$ and excavation method [33]. The section window method is usually used to describe the distribution characteristics of fine roots (usually diameters $<10 \mathrm{~mm}$ ), but it does not properly reflect the range of long, coarse roots. By contrast, the excavation method can reveal all of the roots of a plant. However, this method has several limitations: (i) it is time-consuming and labor-intensive; (ii) it always leads to the death of a plant; and (iii) in practice, it may destroy many fine roots and ruin their distribution patterns. Thus, a com bination of the two methods was used to collect information about both thin and coarse roots.

For the section window method, three vertical trenches were excavated to a depth of $50 \mathrm{~cm}$ around the trees at three different slope locations: upslope of the tree, level with the tree and downslope of the tree [27]. The trees are commonly planted $1 \mathrm{~m}$ apart. According to past research, failure or deformation always starts to happen in the weakest part of the vegetated slope (with less reinforcing effects by roots) $[34,35]$. Thus, the trenches were dug at a distance of $50 \mathrm{~cm}$ from the trunks to investigate the weakest part of the root system [33]. Within each trench, the surface of the profile window was defined 
using a frame with dimensions of $50 \times 50 \mathrm{~cm}$, which was divided into 25 square cells, each with dimensions of $10 \times 10 \mathrm{~cm}$. The roots within each cell were counted, and the root diameter was measured at the same time [14]. During the investigation, all of the roots were divided into four classes according to their diameter: $0-1 \mathrm{~mm}, 1-2 \mathrm{~mm}, 2-5 \mathrm{~mm}$ and 5-10 $\mathrm{mm}$ [36]. Although this method revealed most of the root distribution, several thick roots remained hidden, and therefore, we excavated the entire root system to more clearly reveal its structure and extent (Figure 2). The RAR (root area ratio) was calculated for each cell using the formula:

$$
R A R=\sum_{i=1}^{n} \frac{A_{r i}}{A}
$$

where $n$ is the sample size of the investigated root (i.e., the number of roots), $A_{r i}$ is the cross-sectional area of the roots in the grid cell and $A$ is the reference surface area of a grid cell. $R A R$ values were calculated and analyzed cell by cell in relation to topsoil depth (Figure 3).

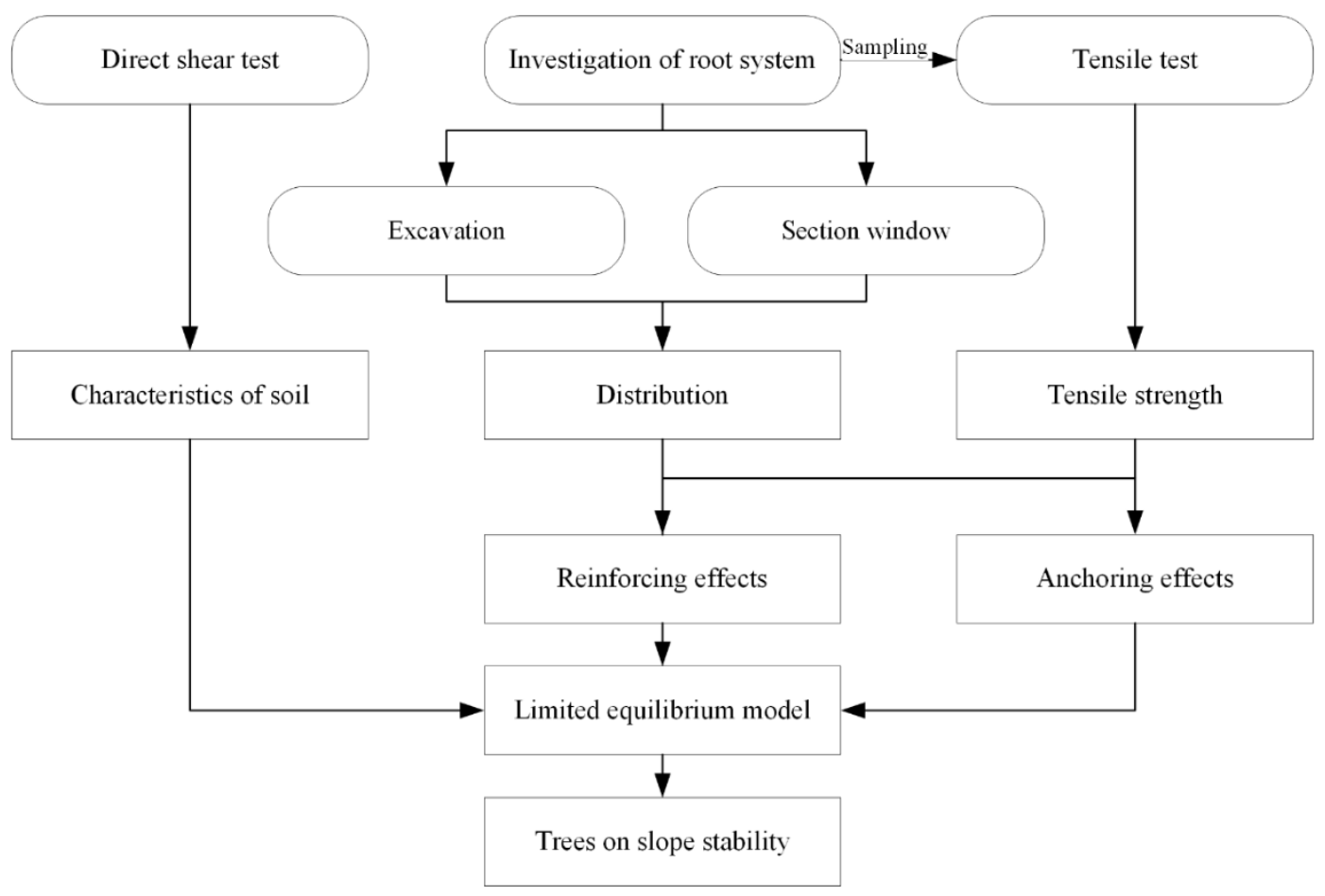

Figure 2. Flowchart illustrating the methodology used in the study.
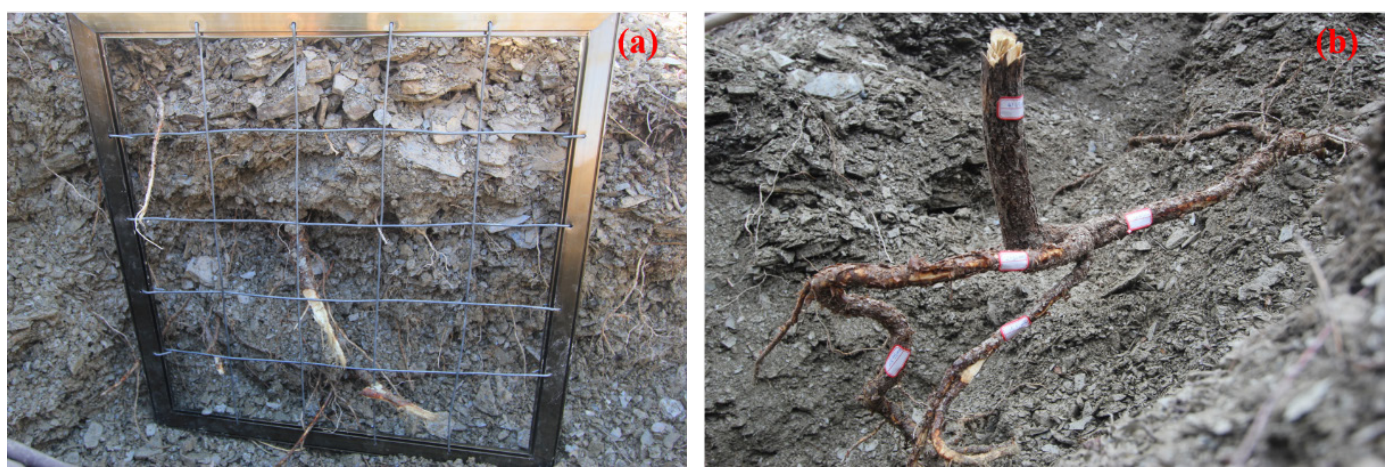

Figure 3. Measurement of the root system (a) by the profile method (the size of the subgrid was $10 \times$ $10 \mathrm{~cm}$ ) and (b) by excavation. 
In the excavation method, the characteristics of the coarse roots were carefully measured and recorded, including the spreading length, diameter and the depth the roots reached within the soil.

\subsection{Measurement of Root Tensile Strength}

During field measurements, living, healthy and unknotted roots of different diameter classes were collected from all four trenches. Mechanical damage to the roots caused by pulling and the use of the excavation tool was minimized. After collection, the root samples were measured and classified by their diameter using Vernier calipers. The samples were stored in containers to prevent damage during transport to the laboratory.

Since the test site was far from the laboratory and root measurements were time consuming, it was impossible to measure the mechanical properties of the collected root samples immediately. Therefore, at the end of each field day, the roots were oven-dried at $60^{\circ} \mathrm{C}$ for $24 \mathrm{~h}$ [27] to reduce the moisture content and minimize root decay. In this study, to ensure that the test results reflected the in situ condition of the sample, all tests were conducted within one week after sampling to maximize the reliability of the tensile test. Tensile force and tensile strength were measured using a universal material testing machine (CSS-4100, developed by Changchun Testing Machines, China). The maximum range of the testing machine was $100 \mathrm{kN}$.

Assuming that rainfall in the study area was sufficient to maintain the roots in a state of near-saturation, the test sample was soaked for several hours before the tensile strength test to maximize its water content $[27,37]$. In the test, the root samples were measured using a $10 \mathrm{~cm}$ gauge, and the loading rate was set to $5 \mathrm{~mm} / \mathrm{s}$. A cork was inserted between the root and the jig to prevent root slippage and damage from the jig of the testing machine [38]. In addition, only when a fracture was located in the middle third of the sample's total length was the test considered successful [36]. The root diameter was measured with Vernier calipers at the root fracture, and each sample was measured three times.

\subsection{In Situ Direct Shear Measurements}

In the study area, the content of coarse particulate matter was very high (a size range of 4-6 cm comprised more than one-half of the samples) [14]. Consequently, the traditional ring shear and small-size straight shear method could not be used to reliably determine the true mechanical properties of the soil because the sample size was too small. Therefore, the shear strength of loose deposits was measured using an in situ direct shear test (the size of the shear box was $500 \times 500 \times 230 \mathrm{~mm}$ ). In accordance with the Geotechnical Engineering Test Manual [39], the direct shear test was completed using the commonly found soil moisture of the slope. The test employed the non-consolidation fast shear method with different vertical loads. The results were estimated using the Mohr-Coulomb failure line (shear strength, normal stress), where the intercept of the failure line represents the soil cohesion, and the angle formed by the failure line and the normal stress axis represents the friction angle. The poorly graded nature of the soils of the study slope made it difficult to measure their mechanical characteristics. Nevertheless, the large size of the shear box used means that the shear experiment results are probably reliable [14]. Table 1 lists the geotechnical parameters used in the bank stability analysis.

Table 1. Parameters of the modeled slope.

\begin{tabular}{cc}
\hline Item & Value \\
\hline Slope $\left(^{\circ}\right)$ & 39 \\
Bulk density $\left(\mathrm{N} / \mathrm{cm}^{3}\right)$ & 17.3 \\
Cohesion $(\mathrm{kPa})$ & 1.05 \\
Friction angle $\left(^{\circ}\right)$ & 44.7 \\
Additional cohesion by roots $(\mathrm{kPa})$ & 15 \\
\hline
\end{tabular}




\subsection{Estimation of the Mechanical Stabilization Effect of Robinia Pseudoacacia on Slope Material}

According to the field survey, both fine roots and coarse roots of the trees could affect the mechanical characteristics of the soil in the top layer. The mechanical stabilization effects of Robinia pseudoacacia on the slopes can be viewed as a combination of two effects: additional cohesion and anchorage, and in this study, we explored both effects. To simplify the analysis, in the field investigation, the root system was classified into two parts according to root diameter depth within the soil. Most of the roots were relatively densely distributed in the top $50 \mathrm{~cm}$ layer, which is the most important layer for increasing soil strength. However, some of the coarse roots can extend to the deeper layers and act to support and fix the plant; at the same time, this part of the root system mainly acts to anchor the surface soil.

\subsubsection{Additional Cohesion Effect of Fine Roots}

The root distribution is relatively dense within the surface soil, which can be viewed as a combined soil and root system composed of a root-soil complex, with the root acting as a flexible material. When failure occurs, the soil shear stress is transferred to the tensile strength of the roots across the failure interface [15], and many methods have been developed to investigate the macroscopic effect. These effects were calculated using the modified WM model, which has an acceptable accuracy [40]. In this model, the reinforcing effect is defined as the additional cohesion $\left(c_{p}\right)$ according to the Mohr-Coulomb failure criterion:

$$
c_{p}=k^{\prime} \frac{\sum_{i=1}^{n} T_{i} n_{i} a_{i}}{A}
$$

where $T_{i}$ is the maximum root tensile strength (MPa) of the diameter class $i, n_{i}$ is the number of roots in the diameter class, $a_{i}$ is the cross-sectional area of the root diameter class $\left(\mathrm{m}^{2}\right), k^{\prime}$ is a correction factor that considers the inclination of the roots crossing the shear plane or the tension crack (the value varies from 1-1.2) and A is the area of soil occupied by the roots $\left(\mathrm{mm}^{2}\right)$. However, much research has revealed that this simple model overestimates the additional cohesion by more than $100 \%$ since it assumes that all the roots are broken at the same time [34,41]. Thus, several coefficients ranging from 0.34 to 0.5 were developed to calibrate $c_{p}$ corresponding to different situations [42]. The modified model is defined as

$$
c_{p}=k^{\prime \prime} k^{\prime} \frac{\sum_{i=1}^{n} T_{i} n_{i} a_{i}}{A}
$$

where $k^{\prime \prime}$ is the calibration value of the model. In the present study, $k^{\prime \prime}$ was set to 0.4 (Preti and Schwarz, 2006).

\subsubsection{Anchoring Effect of Coarse Roots}

Natural soils usually develop cracks and structures, and if bolts, anchor cables and soil nails are inserted in the soil, these reinforcement structures can disperse and transfer the soil load, limit soil deformation and increase soil strength. If bolts and other reinforcing structures are inserted through the surface of loose soil material and inserted into the stable bedrock, which provides internal stability, they can anchor the unstable surface soil to the deep stable layers and thus prevent surface slippage and enhance the stability of the entire solum. Field investigations have revealed that each of the sampled trees have developed at least one coarse lateral root. Those coarse roots usually have a high tensile strength and can penetrate the surface soil to a considerable depth (some plant roots are able to penetrate bedrock fissures). To quantify the effects of plant anchorage, several workers established a model based on the actual physical mechanisms to study the anchoring effect of the root system [43]. The magnitude of the tensile force required to destroy the root-soil complex is

$$
F=2 \pi R \cdot \alpha \tau \cdot X
$$


where $R$ is the average diameter of the roots below the surface, $\alpha$ is the friction coefficient between the soil and the root, $\tau$ is the strength of the soil and $X$ is the depth of the fracture of the soil-root complex. We calculated the peak tensile force of the root as

$$
F_{r}=\pi R^{2} \cdot \sigma
$$

where $R$ is the diameter of the root and $\sigma$ is its tensile strength.

When failure of the soil occurs, the strength of the root may be insufficient to resist the tensile force. Thus, the relationship between the tensile force $F r$ of the root system and the frictional force $F$ between the root and the soil can be defined as follows: when $F r>F s$, the root will be pulled out, and when $F r \leq F s$, the root will break. Based on the above formula, $L_{R B}$ is the critical broken length of the root-soil complex and is calculated as

$$
L_{R B}=\frac{\sigma \cdot R}{2 \cdot \alpha \cdot \tau}
$$

This formula reflects the relationship between the range and strength of the anchoring effect and the strength of the soil: when the length of the root exceeds $L_{R B}$, the anchoring effect of the root is substantially reduced. Long roots will be broken near $L_{R B}$, while short roots will be pulled out.

\subsection{Calculation of Slope Stability}

According to the field situation, the height of the simulated slope was set to $15 \mathrm{~m}$ and the slope angle to $40^{\circ}$ (Figure 4). The slope was divided into three parts: upper, middle and lower, and the influence of planting trees on slope stability was calculated. Three types of model material were used: soil, a root-soil complex and a root-soil complex with anchoring coarse roots. The limit equilibrium method has the advantages of a clearly defined physical mechanism and a relatively simple calculation process and is the most commonly used method to calculate the stability of a soil slope. In this method, the slope is assumed to be a horizontal cylinder, and several slip surfaces are assumed. The soil above the sliding surface is divided into several strips using the strip method. For a single soil bar or for the entire soil body, an equation is established based on the force balance, moment balance and boundary conditions. In the calculation process, the stability coefficient of the finite slope is defined as the ratio of the anti-sliding force to the sliding force, and the safety factor corresponding to each assumed sliding surface is calculated using the trial method. The slip surface with the lowest safety factor is defined as a dangerous slip surface, and the FoS of the sliding surface corresponds to the safety factor of the slope in this state [44]. When FoS $>1$, the slope is regarded as stable; when FoS $=1$, the slope is in the critical state; and when FoS $<1$, the slope is unstable. Without considering the stress-strain relationship of the soil, many researchers have used different assumptions based on the limit equilibrium method to simplify the problem and solve stationary problems. Several calculation methods can be used, such as the Ordinary/Fellenius method [45], Bishop/Bishop corrected method [46], Janbu method [47], Morgenstern-Price method [48] and the imbalance thrust force method. In the present study, we used Slide 6.0 software to calculate the factor of stability (FoS) of the slope. Three methods were used: Ordinary /Fellenius (OF), Bishop (BS) and Morgenstern-Price (MP). The results were then compared to assess their validity.

The effect of fine roots on slope material is mainly via their provision of additional cohesion [18], which is mainly distributed within the soil layer within a depth range of $0.0-0.5 \mathrm{~m}$. Therefore, this layer was defined as the soil-root complex, and it had the same internal friction angle as the soil, while the cohesion was set as the sum of the soil cohesion and the additional cohesion from fine roots. Within the software, the anchoring effect of coarse roots was then represented in the form of bolts within the slope. The stress-strain relationship of the bolts (i.e., coarse roots) was obtained from the tensile tests (Figure 5). 


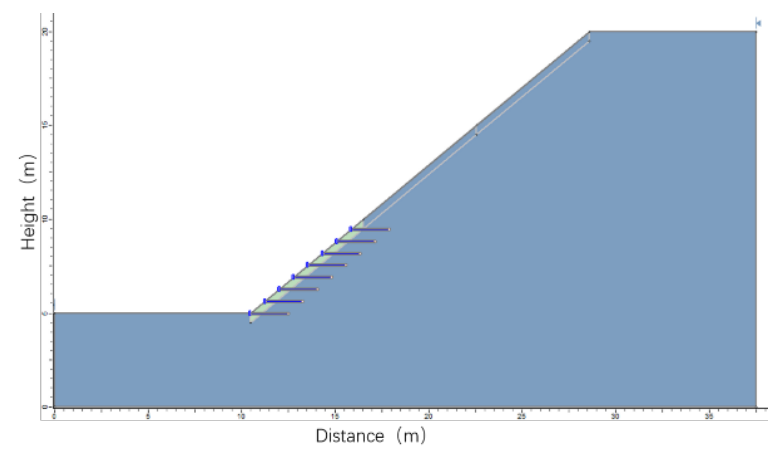

Figure 4. Geometry of the modeled slope used for the calculations.

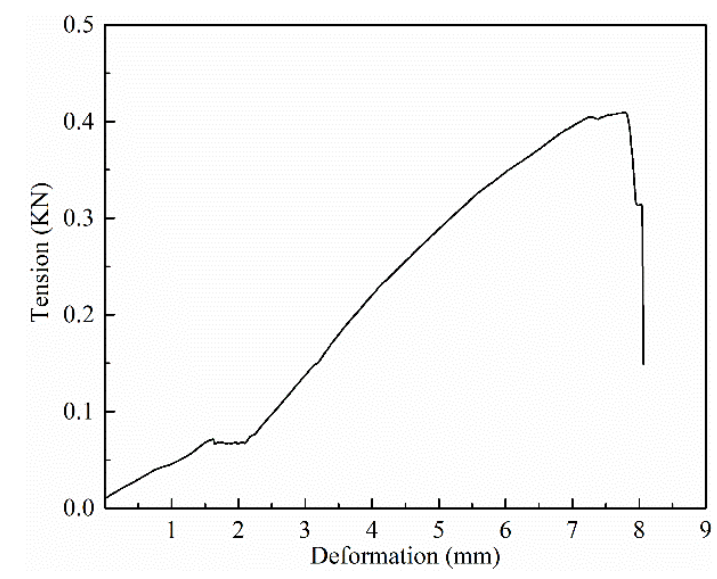

Figure 5. Relationship between tensile force and deformation distance of large roots of Robinia pseudoacacia on the studied slope.

\section{Results}

\subsection{Root Distribution}

Robinia pseudoacacia is classified as one of the tree species with a horizontally distributed root system since its roots mainly expand horizontally without the development of large vertical roots. With the increase in sampling depth, the number of root systems of different diameter classes exhibited specific characteristics (Figure 6, Table 2). The number of fine roots $(\mathrm{d} \leq 1.0 \mathrm{~mm})$ decreased with increasing depth and showed a significant exponential trend. When the root diameter exceeded $1.0 \mathrm{~mm}$, the number of roots in the section either increased or increased initially and then decreased with increasing depth. This result differs substantially from those of other studies. Thus, we assumed that the distribution characteristics of the root system of Robinia pseudoacacia on the slopes were affected by habitat and had specific local characteristics. The number of fine roots $(\mathrm{d} \leq 1.0 \mathrm{~mm})$ in the root system represented $88.4 \%, 81.3 \%$ and $92.5 \%$ of the total number of roots in the three directions relative to the tree (upslope, level and downslope, respectively). It has been shown that, although their diameter is small, the density and quantity of roots thinner than $1.0(\mathrm{~d} \leq 1.0) \mathrm{mm}$ is large. Thus, they have a strong adhesion to the soil particles and have a correspondingly strong effect on soil strength. In addition, in the different directions relative to the tree (upslope, level and downslope), the root distributions for different diameter classes were substantially different. For roots thinner than $1.0 \mathrm{~mm}$, the difference in root distribution for the three directions was not significant $(\mathrm{F}=1.567, p=0.248$, ANOVA). In contrast, for the other roots, as their diameter increased, the difference in root distribution for the three relative directions also increased (Table 3): when the root diameter exceeded $2.0 \mathrm{~mm}$, the number of root distributions differed significantly in the following order: parallel $>$ upslope $>$ downslope. 


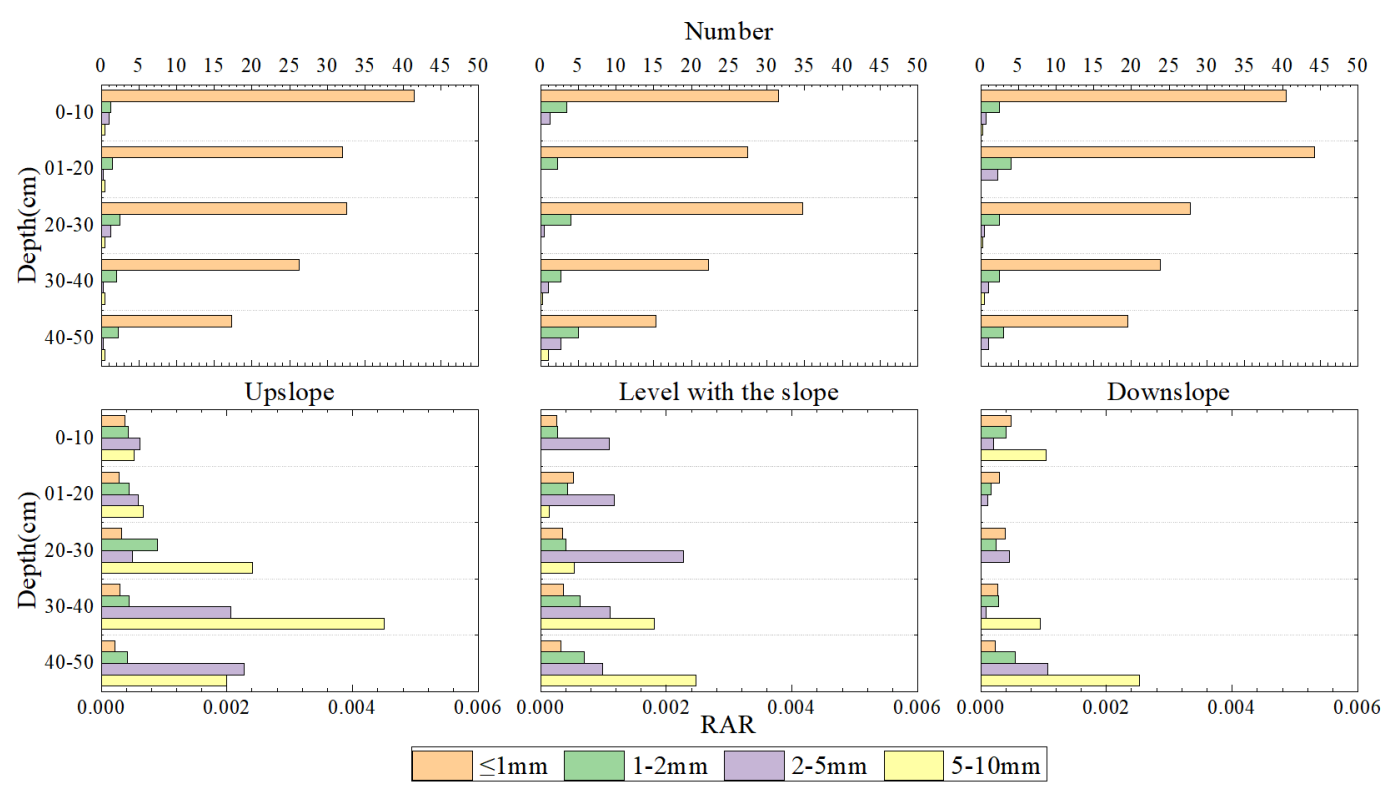

Figure 6. Distribution of root numbers and root area ratios (RARs) at different depths and directions relative to the tree.

Table 2. Relationship between root distribution and soil depth.

\begin{tabular}{ccc}
\hline Root Diameter Classes & Fitting Function & Correlation Coefficient \\
\hline $\mathrm{d} \leq 1.0 \mathrm{~mm}$ & $\mathrm{Rd} 1=149.71 \mathrm{e}^{-0.192 \mathrm{~d}}$ & $\mathrm{R}^{2}=0.9175$ \\
$1.0 \mathrm{~mm} \leq \mathrm{d} \leq 2.0 \mathrm{~mm}$ & $\mathrm{Rd} 2=6.8147 \mathrm{e}^{0.0626 \mathrm{~d}}$ & $\mathrm{R}^{2}=0.4261$ \\
$2.0 \mathrm{~mm} \leq \mathrm{d} \leq 5.0 \mathrm{~mm}$ & $\mathrm{Rd} 3=0.34 \mathrm{~d}^{2}-1.86 \mathrm{~d}+4.65$ & $\mathrm{R}^{2}=0.8818$ \\
$5.0 \mathrm{~mm} \leq \mathrm{d} \leq 10.0 \mathrm{~mm}$ & $\mathrm{Rd} 4=0.09 \mathrm{z}^{2}-0.31 \mathrm{z}+0.9$ & $\mathrm{R}^{2}=0.9153$ \\
\hline
\end{tabular}

Table 3. Differences in the distribution of different root size classes in relation to direction around the tree on the slope (AVOVA, SPSS 22).

\begin{tabular}{ccc}
\hline Diameter Classes & F Value & $p$ \\
\hline $\mathrm{d} \leq 1.0 \mathrm{~mm}$ & 1.567 & 0.248 \\
$1.0 \mathrm{~mm} \leq \mathrm{d} \leq 2.0 \mathrm{~mm}$ & 2.567 & 0.118 \\
$2.0 \mathrm{~mm} \leq \mathrm{d} \leq 5.0 \mathrm{~mm}$ & 6.20 & $0.014^{\mathrm{a}}$ \\
$5.0 \mathrm{~mm} \leq \mathrm{d} \leq 10.0 \mathrm{~mm}$ & 6.50 & $0.028^{\mathrm{a}}$ \\
\hline
\end{tabular}

a Significant at $p=0.05$.

Our investigation showed that, for each of the trees that were investigated by the excavation method, there was at least one long, coarse root that penetrated both deeply within the soil and almost horizontally. The diameter of the coarse roots was measured every $0.3 \mathrm{~m}$ away from the trunk and recorded (Figure 7). The results show that the mean diameter of the root within soil could still reach $5.0 \mathrm{~mm}$ when the length reached $2.0 \mathrm{~m}$. 


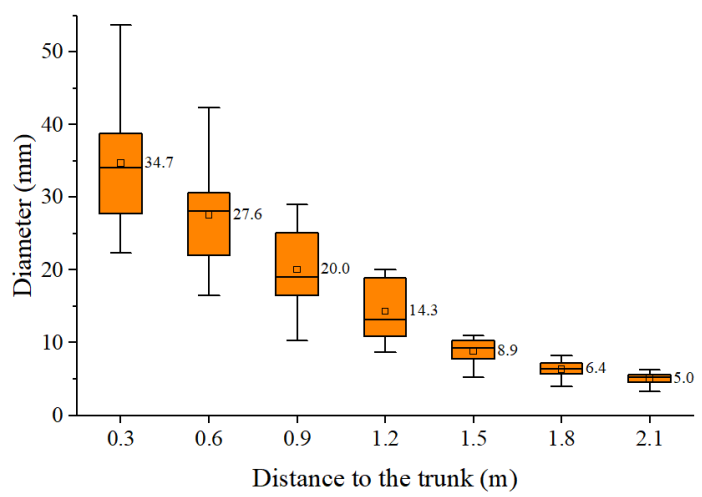

Figure 7. Relationship between the diameter of coarse roots and their distance from the trunk.

\subsection{Tensile Strength}

The peak tension of the root samples increased with increasing root diameter, and the relationship was well-described by a power function (Figure 8). Although the data were scattered, the tensile strength exhibited a decreasing trend with increasing root diameter; however, the relationship could not be described by a power function.
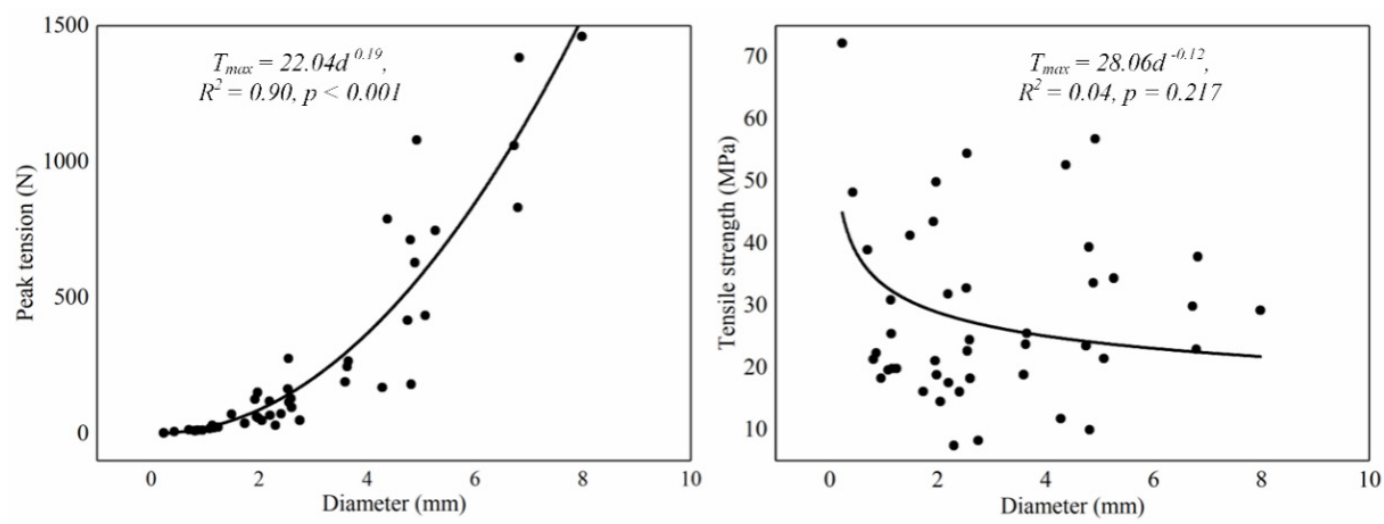

Figure 8. Relationship between root diameter and peak tension (left) and the relationship between root diameter and tensile strength (right) for Robinia pseudoacacia on the study slope. Power-series regression relationships.

\subsection{The Additional Cohesion and Anchoring Effect of Roots}

Based on the results of the field investigation and tensile tests, the additional cohesion of the fine roots was calculated using the modified WM model. The relatively thin root system (less than $10 \mathrm{~mm}$ in diameter) was mainly distributed at a depth of $0.5 \mathrm{~m}$ from the surface on different slope segments (i.e., upper slope, midslope and lower slope) and different depths $(0-50 \mathrm{~cm})$. The contribution to soil cohesion is shown in Figure 9. The additional cohesive effect of fine roots on the soil in the upper, middle and lower slope segments was statistically evaluated. The results showed no significant difference $(p=0.612)$, and the additional cohesion values (mean \pm standard deviation) were $13.41 \pm 9.53 \mathrm{kPa}$, $12.76 \pm 5.40 \mathrm{kPa}$ and $17.48 \pm 5.56 \mathrm{kPa}$ for the upper, middle and lower slope segments, respectively. Therefore, it was assumed in the simulation calculation that the contribution of mature plants to the cohesion of loose deposits was $15 \mathrm{kPa}$. 


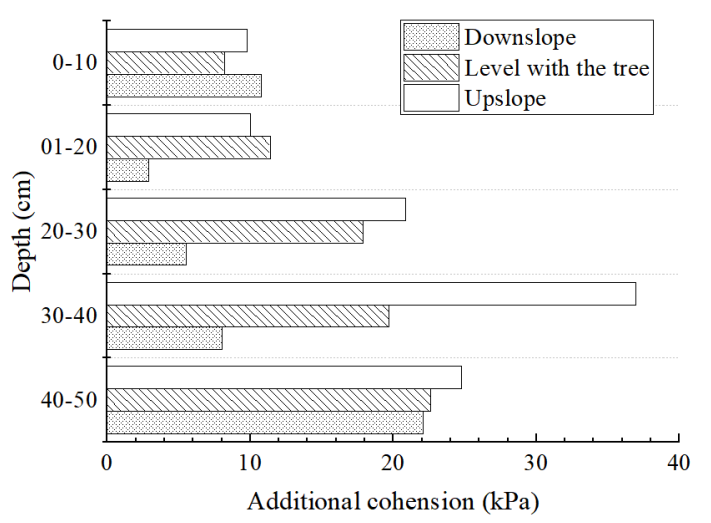

Figure 9. Distribution of additional cohesion of fine roots (diameter $<10 \mathrm{~mm}$ ) to soil depth.

The field investigations showed that the long, coarse roots spread almost horizontally within the soil. Since the slope angle was $39^{\circ}$, the bulk density of the loose deposits was $1.7 \mathrm{~g} / \mathrm{cm}^{3}$, and the length of the root system within the soil was more than $2.0 \mathrm{~m}$. In addition, the diameter of the root was about $5.0 \mathrm{~mm}$. At the same time, according to the internal friction angle and cohesive force of the soil (Table 3), the shear strength of the soil at the position of $2.0 \mathrm{~m}$ horizontally within the slope could be obtained from the Mohr-Coulomb formula, and the result was $30.11 \mathrm{kPa}$. The performance versus tensile strength relationship could then be calculated by inserting the tensile strength and diameter data into Formula (6). In the extreme case where the coefficient of friction was 1.0, the smallest critical failure length $L_{R B}$ of the root was $1.99 \mathrm{~m}$. This result demonstrates that roots with a length of $1.99 \mathrm{~m}$ on the slope had a strong anchoring effect.

\subsection{Calculation of Slope Stability}

Three methods were used to calculate slope stability, depending on whether the anchoring effects of roots were taken into consideration and on different planting sites. The results are shown in Table 4 . In the case of the absence of vegetation, the FoS results were 1.157 (OF method), 1.149 (BS method) and 1.192 (MP method). In the absence of an anchorage effect, Robinia pseudoacacia could have a positive effect on slope stability, except in locations where planted Robinia pseudoacacia stands were on the upper part of the slope. Overall, however, taking anchoring effects into consideration, planting on all locations on the slope could increase slope stability. Among the three calculation methods, the value calculated from the BS method was the largest, while the one from the OF method was the smallest relatively. The main reason for the difference in the results is that the OF method assumes that the shape of the sliding surface is a cylindrical surface without considering the interaction between soil strips. Meanwhile, the BS and MP method take the forces between the soil strips into consideration.

Table 4. Factor of stability (FoS) of the slope under different vegetation conditions.

\begin{tabular}{ccccc}
\hline \multirow{2}{*}{ Planted Location } & With/Without Anchorage & \multicolumn{3}{c}{ Stability Factor } \\
\cline { 3 - 5 } & & OF & BS & MP \\
\hline Without vegetation & - & 1.157 & 1.149 & 1.192 \\
\hline Upslope & Without & 1.149 & 1.186 & 1.182 \\
Middle slope & Without & 1.159 & 1.197 & 1.176 \\
Lower slope & Without & 1.163 & 1.192 & 1.197 \\
All & Without & 1.202 & 1.27 & 1.266 \\
\hline Upslope & With & 1.158 & 1.196 & 1.195 \\
Middle slope & With & 1.159 & 1.199 & 1.189 \\
Lower slope & With & 1.181 & 1.216 & 1.211 \\
All & With & 1.208 & 1.277 & 1.275 \\
\hline
\end{tabular}


The difference between the FoS of different planting scenarios on the slopes was calculated using the three methods. It is clear that the results obtained by the BS method were the most reliably successful among the three for estimating the reinforcement effect of plant roots; this is because, compared with the other two methods, the BS method emphasizes the interaction between the soil units.

The upper part of an unstable slope was prone to extensional deformation, while the anchoring effect of the roots could limit such deformation to a certain extent (Figure 10a). When the trees were located in the middle of the slope, since the sliding surface here was deeper, the effect of the roots on sliding was weaker (Figure 10b), and thus, the anchoring effect on slope stability was not significant. When the trees were located on the lower part of the slope, the increase in slope stability was the most obvious, and in this case, the calculated potential sliding surface was moved to the upper part of the slope (Figure 10c). When the entire slope surface was planted with Robinia pseudoacacia, the entire surface would be reinforced, so the potential sliding surface would pass through the coarse roots (Figure 10d). Since root-reinforced soils have higher shear strength, this phenomenon could improve slope stability.

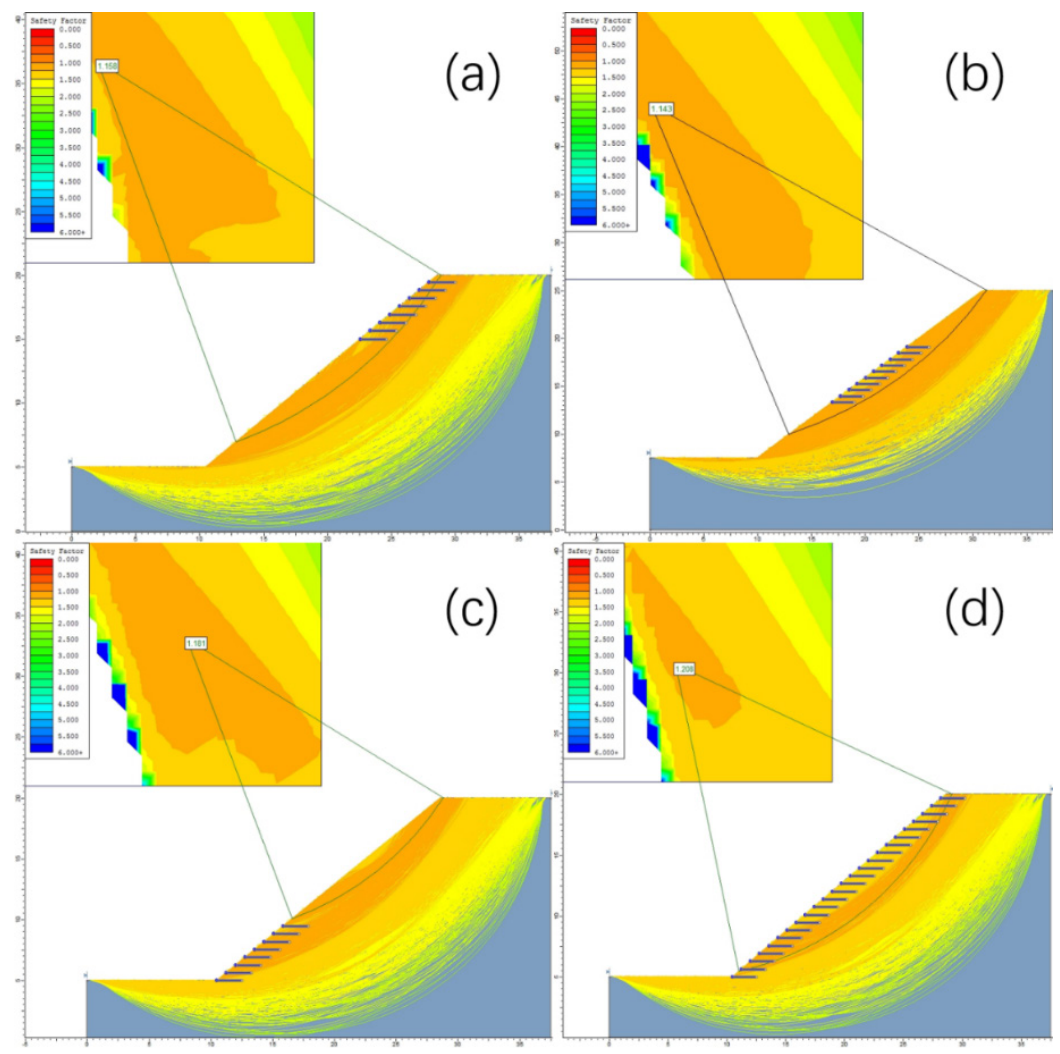

Figure 10. Distribution of the potential sliding surface in relation to position on the slope under vegetation at different locations: (a) planted on the top part of the slope, (b) planted on the middle part of the slope, (c) planted on the lower part of the slope and (d) planted on the entire slope surface. The curves show the sliding surface defined automatically by the software.

\section{Discussion}

\subsection{Characteristics of Root Distributions on the Study Slope}

The root system is one of the most important vegetative organs of seed plants, which not only provides water, minerals and other essential nutrients for plant growth but also fixes and supports the plant on the ground surface. While ensuring the growth of plants, the roots can also fix loose material and increase its resistance to erosion. As the elastic modulus of a root is much larger than that of the loose soil, deformation occurs, and the friction between soil and the root can limit the extent 
of deformation. Therefore, the distribution characteristics, mechanical properties and physiological processes of plant roots are the most important factors for assessing the role of plants in reinforcing soil.

In ideal cases where the soil texture is uniform and the slope is gentle, the distribution of the roots should be isotropic in the horizontal plane. However, since the distribution of water and nutrients in the soil on steep slopes is strongly affected by gravity, there are significant differences in the distribution of plant roots, and the actual root growth may be heterogeneous. Fine roots $(\mathrm{d} \leq 1.0 \mathrm{~mm})$ are the main organs for absorbing water and nutrients, and the distribution of fine roots in a previous study exhibited an obvious relationship with the three directions relative to the tree (i.e., upslope, level and downslope) [49]. Robinia pseudoacacia is classified as a species with a horizontally distributed root system. It has been demonstrated that the shape of the root system of Robinia pseudoacacia on loess slopes with relatively good water and nutrient conditions should be fan-shaped or semicircular and tends to extend downslope. However, the root distribution of the plants investigated in the present study exhibited different characteristics. First, the vertical distribution of fine roots $(\mathrm{d} \leq 1.0 \mathrm{~mm})$ showed no significant downward trend, and in all of the three relative directions to the tree, the horizontal distribution of the roots was very similar. Although the slope in the study area reached almost $40^{\circ}$, the horizontal distribution of the fine roots did not vary significantly. This indicates that the distribution of water in loose debris is not dominated by the slope due to the abundant rainfall in the area. Thus, water and nutrients are not the main limiting factors for the growth of Robinia pseudoacacia in the region, and the similar distribution of fine roots in different slope directions reflects the ability of the roots to absorb sufficient water and nutrients to supply the plant. Second, the distributions of other root diameter classes $(2.0 \mathrm{~mm} \leq \mathrm{d} \leq 5.0 \mathrm{~mm}, 5.0 \mathrm{~mm} \leq \mathrm{d} \leq 10.0 \mathrm{~mm})$ also exhibited distinctive characteristics at different depths and directions relative to the trunk position. As the main part of the whole plant, the distribution of these roots had a significant slope effect. The quantity of roots in the upslope and level directions was 1.63 times and 2.06 times greater than that in the downslope direction, respectively. This indicates that, in the case of loose deposits with poor stability, a principal requirement of the plant is to fix itself in position, which has already been proven by other scholars [50].

The results show that the distribution of roots with a diameter $>2 \mathrm{~mm}$ dominated the RAR in the root system. However, strictly speaking, the RAR did not decrease as the depth increased. In some cases, the RAR increased with increasing depth. Many researchers have demonstrated that as plants mature, root morphology may be affected by soil characteristics (such as moisture and nutrient status) [51]. Since the soils in the studied banks were poorly developed with abundant gravel and were unstable, the fine roots in the top layer were more likely to be damaged or destroyed before they could grow up to the thick ones. Thus, the amount of thick roots was relatively high in the lower layers.

\subsection{Tensile Strength of the Roots on the Slope}

Peak tension and tensile strength are important factors influencing the reinforcing effect of the root system. The greater the peak tension, the greater the anchoring effect, and the greater the tensile strength, the more the soil is reinforced. Studies have shown that the tensile strength of plant roots is related to the content of root cells and the lignin, cellulose and hemicellulose content of the roots [51]. It is noteworthy that in the study area, the vegetation and its root systems were substantially affected by disturbances, including soil instability and physical damage. Such disturbances and the root composition may be an important reason for the scattered data obtained in the study. In addition, due to the specific habitat in the study area, the loose deposits lacked stability, and typically, there was an accumulation of surface material. As a result, the growth of plant roots was hindered, and they were compressed by gravel, which may lead to the continuous development of root callus and phloem tissue and changes in cell structure and material composition, which could substantially affect the tensile strength. Those may be the main reasons for the nonpower function relationship between diameter and tensile strength, in contrast to the findings of other studies [37]. 


\subsection{Influence of Root Anchorage on Slope Stability}

Deeper plant roots can fix both the plant and the shallow soil within the relatively stable layer, and the effect of the plants on the slope material is similar to that of a prestressed bolt, resulting in a significant increase in soil stability. For shallow landslides, the shearing forces of the soil will be exerted on the vertical root system, causing reactionary shear stress to prevent slope deformation.

In the calculation of slope stability under conditions of planting Robinia pseudoacacia on the upper part of the slope, the results of the two stability calculation methods (the OF and MP methods) show that slope stability was decreased under the influence of vegetation (Figure 11). However, in this simulation scenario, the loading from the weight of the trees was neglected. The field investigation showed that, at the top of the slope, the Robinia pseudoacacia plantation did not adversely affect slope stability. Thus, the simulation result was inconsistent with the actual situation. When taking the anchorage effect into consideration, the calculation results show that the Robinia pseudoacacia plantation on the upper part of the slope could also increase slope stability. Coarse roots (maximum diameter up to $78 \mathrm{~mm}$ ) could strengthen the slope surface and limit the movement of surface debris. Therefore, it is important to consider the effect of the anchoring effect on the calculation results when estimating the effect of plant roots on slope stability.
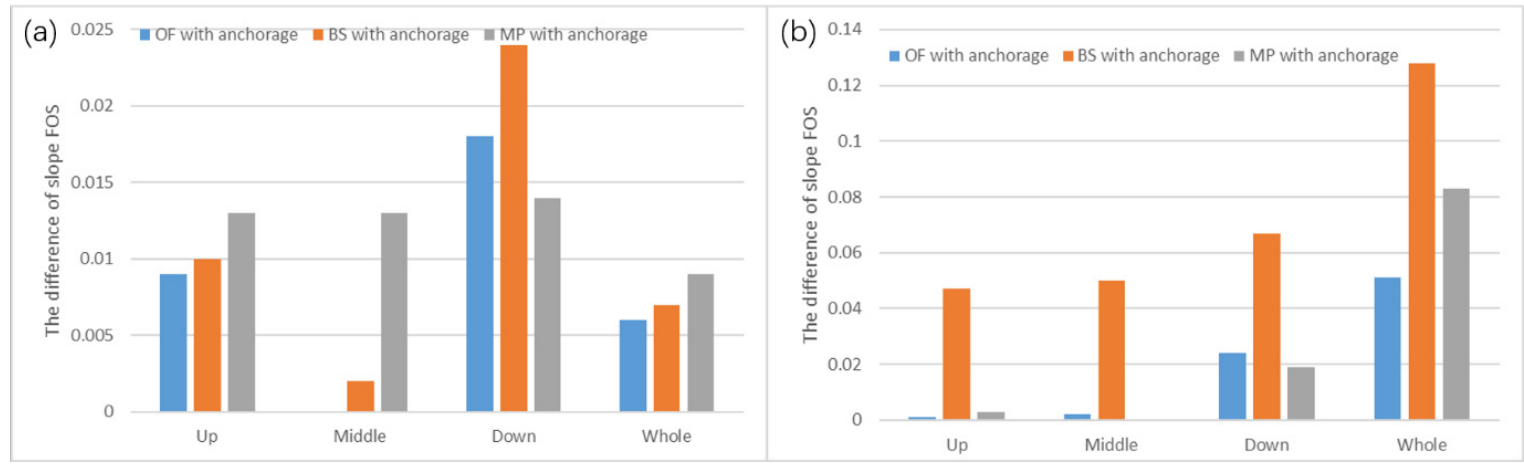

Figure 11. (a) Effect of root anchorage on FoS for different slope locations (upper, middle and lower) and $(\mathbf{b})$ the differences in slope FoS for trees at different locations.

When considering the anchoring effect of the root system, Robinia pseudoacacia had a positive effect on slope stability, but this effect was related to the location of the vegetation on the slope. When Robinia pseudoacacia was located on the upper part of the slope, the anchoring effect of coarse roots played a significant role in improving slope stability.

\subsection{Effect of Planting Location on Slope Stability}

The cohesion between the particles was relatively weak, and therefore, the elastic modulus of the soil was very low, and under the influence of gravity, pore pressure or other stresses, the soil was prone to deformation, which may lead to instability and shear damage. Therefore, for Robinia pseudoacacia, the optimum planting solution to enhance slope stability was to plant the trees on the entire surface of the slope to make the maximum use of trees in improving slope stability. However, in reality, due to factors such as cost, accessibility and logistical difficulties, this strategy is often unrealistic. In this case, planting on the lower slope may be the next best choice. Planting trees at this location not only reduced the movement of slope material to drainage channels, but it also stabilized the material at the foot of the slope and reduced the erosion of the slope by water flow in the channel, and consequently, the stability of the slope was improved.

\section{Conclusions}

Robinia pseudoacacia is well-suited to planting on the metastable slope in the study area due to the distinctive local environmental conditions, and it develops a widespread and robust root system. 
Based on our careful investigation of root morphology and root strength, we developed a numerical model that simultaneously considered the additional cohesion and anchoring effects of vegetation on a slope comprising coarse-grained soil material. The results show that the trees could stabilize the metastable slope and that anchoring effects should not be neglected in assessing the mechanical influence of trees on slope stability. The anchoring effect of the plant roots significantly affected the interaction between the sliding and stable part of the soil. Thus, the calculated stability was higher. However, when calculating the influence of planting position on slope stability, the three stability calculation methods showed similar trends. When the entire surface of the slope was planted with Robinia pseudoacacia, all of the surface material on the slope was reinforced, and the contribution to the slope stability was the most obvious. If Robinia pseudoacacia was planted only on the lower part of the slope, the roots could strengthen the head of the slope and cause the sliding surface to move upwards, and in this case, the contribution to slope stability was ranked second amongst the three. When Robinia pseudoacacia was planted in the middle of the slope, the contribution to slope stability was the least since the sliding surface was deeper in this part of the slope and the roots could barely penetrate the sliding body, and therefore, it was more difficult for the soil near the sliding surface to be affected. When the trees were planted at the top of the slope, the roots could inhibit slippage in this part of the slope, and they also had a positive effect on slope stability.

It is important to note that the effect of the root system on slope stability was limited in the study area since the impact of plants on slope stability was only $4-11 \%$ in most scenarios. Thus, the main effect of plants on similar slopes is to control soil erosion. In addition, Robinia pseudoacacia can protect the local habitat by stabilizing the surface soil and shielding other plants from damage by falling debris. As a result, Robinia pseudoacacia is one of the key species for use in ecological restoration in the study region.

Author Contributions: Conceptualization, S.W. and X.M.; methodology, S.W. and G.C.; software validation, M.Z. and Q.Y.; formal analysis, R.Z.; investigation, R.Z., Y.L. and B.W.; data curation, M.Z.; writing-original draft preparation, S.W. and M.Z.; writing—review and editing, X.M.; visualization, S.W.; supervision, X.M.; project administration, X.M. All authors have read and agreed to the published version of the manuscript.

Funding: This study was supported by the National Key Research and Development Program of China (grant no. 2017YFC1501005), the National Natural Science Foundation of China (grants 41702292 and 41661144046), the Key Technology Research and Development Program of the Ministry of Gansu Province, China (grant 1604FKCA098) and the China Geological Survey (grant no. DD20190268 [2020]012, DD20190646 and DD20160262).

Acknowledgments: We thank Muqi Xiong, Zhijie Cui, Yi Zhang, Feng Qing and Yan Zhao for their assistance during the study. We are grateful to the reviewers and editors for their constructive comments, which have substantially improved the manuscript.

Conflicts of Interest: The authors declare that they have no conflicts of interest with respect to this work. We declare that we do not have any commercial or associative interest that represents a conflict of interest in connection with the work submitted.

\section{References}

1. Cohen, D.; Lehmann, P.; Or, D. Fiber bundle model for multiscale modeling of hydromechanical triggering of shallow landslides. Water Resour. Res. 2009, 45, 1-20. [CrossRef]

2. Schmidt, K.; Roering, J.; Stock, J.; Dietrich, W.; Montgomery, D.; Schaub, T. The variability of root cohesion as an influence on shallow landslide susceptibility in the Oregon Coast Range. Can. Geotech. J. 2001, 38, 995-1024. [CrossRef]

3. Li, Y.; Wang, Y.; Ma, C.; Zhang, H.; Wang, Y.; Song, S.; Zhu, J. Influence of the spatial layout of plant roots on slope stability. Ecol. Eng. 2016, 91, 477-486. [CrossRef]

4. Temgoua, A.G.T.; Kokutse, N.K.; Kavazović, Z. Influence of forest stands and root morphologies on hillslope stability. Ecol. Eng. 2016, 95, 622-634. [CrossRef]

5. Kim, J.H.; Fourcaud, T.; Jourdan, C.; Maeght, J.L.; Mao, Z.; Metayer, J.; Meylan, L.; Pierret, A.; Rapidel, B.; Roupsard, O. Vegetation as a driver of temporal variations in slope stability: The impact of hydrological processes. Geophys. Res. Lett. 2017, 44, 4897-4907. [CrossRef] 
6. Shen, P.; Zhang, L.M.; Chen, H.X.; Gao, L. Role of vegetation restoration in mitigating hillslope erosion and debris flows. Eng. Geol. 2017, 216, 122-133. [CrossRef]

7. Coppin, N.; Richards, I.G. Use of Vegetation in Civil Engineering; Butterworth-Heinemann: Oxford, UK, 1990.

8. Ni, J.J.; Leung, A.K.; Ng, C.W.W.; Shao, W. Modelling hydro-mechanical reinforcements of plants to slope stability. Comput. Geotech. 2018, 95, 99-109. [CrossRef]

9. Das, G.K.; Hazra, B.; Garg, A.; Ng, C.W.W. Stochastic hydro-mechanical stability of vegetated slopes: An integrated copula based framework. CATENA 2018, 160, 124-133. [CrossRef]

10. Zhu, H.; Zhang, L.M.; Xiao, T.; Li, X.Y. Enhancement of slope stability by vegetation considering uncertainties in root distribution. Comput. Geotech. 2017, 85, 84-89. [CrossRef]

11. Li, K.; Zhang, G. Soil and Water Conservation Forest; China Science Publishing: Beijing, China, 2012.

12. Xu, M.; Gao, D.; Fu, S.; Lu, X.; Wu, S.; Han, X.; Yang, G.; Feng, Y. Long-term effects of vegetation and soil on the microbial communities following afforestation of farmland with Robinia pseudoacacia plantations. Geoderma 2020, 367, 114263. [CrossRef]

13. Xu, Y.; Wang, T.; Li, H.; Ren, C.; Chen, J.; Yang, G.; Han, X.; Feng, Y.; Ren, G.; Wang, X. Variations of soil nitrogen-fixing microorganism communities and nitrogen fractions in a Robinia pseudoacacia chronosequence on the Loess Plateau of China. CATENA 2019, 174, 316-323. [CrossRef]

14. Wang, S.; Meng, X.; Chen, G.; Guo, P.; Xiong, M.; Zeng, R. Effects of vegetation on debris flow mitigation: A case study from Gansu province, China. Geomorphology 2017, 282, 64-73. [CrossRef]

15. Gray, D.H.; Sotir, R.B. Biotechnical and Soil Bioengineering Slope Stabilization: A Practical Guide for Erosion Control; Wiley-Interscience: Hoboken, NJ, USA, 1996.

16. Zhang, C.-B.; Chen, L.-H.; Liu, Y.-P.; Ji, X.-D.; Liu, X.-P. Triaxial compression test of soil-root composites to evaluate influence of roots on soil shear strength. Ecol. Eng. 2010, 36, 19-26. [CrossRef]

17. Wu, T.H.; McKinnell Iii, W.P.; Swanston, D.N. Strength of tree roots and landslides on Prince of Wales Island, Alaska. Can. Geotech. J. 1979, 16, 19-33. [CrossRef]

18. Wu, T.H. Root reinforcement of soil: Review of analytical models, test results, and applications to design. Can. Geotech. J. 2013, 50, 259-274. [CrossRef]

19. Preti, F.; Schwarz, M. On root reinforcement modelling. In Geophysical Research Abstrsacts; European Geosciences Union: Munich, Germany, 2006; pp. 2-7.

20. Hubble, T.C.T.; Airey, D.W.; Sealey, H.K.; De Carli, E.V.; Clarke, S.L. A little cohesion goes a long way: Estimating appropriate values of additional root cohesion for evaluating slope stability in the Eastern Australian highlands. Ecol. Eng. 2013, 61, 621-632. [CrossRef]

21. Schutten, J.; Dainty, J.; Davy, A.J. Root Anchorage and Its Significance for Submerged Plants in Shallow Lakes. J. Ecol. 2010, 93, 556-571. [CrossRef]

22. Dupuy, L.; Fourcaud, T.; Stokes, A. A numerical investigation into the influence of soil type and root architecture on tree anchorage. Plant Soil 2005, 278, 119-134. [CrossRef]

23. Fourcaud, T.; Ji, J.N.; Zhang, Z.Q.; Stokes, A. Understanding the Impact of Root Morphology on Overturning Mechanisms: A Modelling Approach. Ann. Bot. 2008, 101, 1267-1280. [CrossRef]

24. Kamimura, K.; Kitagawa, K.; Saito, S.; Mizunaga, H. Root anchorage of hinoki (Chamaecyparis obtuse (Sieb. Et Zucc.) Endl.) under the combined loading of wind and rapidly supplied water on soil: Analyses based on tree-pulling experiments. Eur. J. For. Res. 2012, 131, 219-227. [CrossRef]

25. Sun, H.-L.; Li, S.-C.; Xiong, W.-L.; Yang, Z.-R.; Cui, B.-S.; Tao, Y. Influence of slope on root system anchorage of Pinus yunnanensis. Ecol. Eng. 2008, 32, 60-67. [CrossRef]

26. Li, S.-C.; Sun, H.-L.; Yang, Z.-R.; Xiong, W.-L.; Cui, B.-S. Root anchorage of Vitex negundo L. on rocky slopes under different weathering degrees. Ecol. Eng. 2007, 30, 27-33. [CrossRef]

27. Ji, J.; Kokutse, N.; Genet, M.; Fourcaud, T.; Zhang, Z. Effect of spatial variation of tree root characteristics on slope stability. A case study on Black Locust (Robinia pseudoacacia) and Arborvitae (Platycladus orientalis) stands on the Loess Plateau, China. CATENA 2012, 92, 139-154. [CrossRef]

28. Stokes, A.; Norris, J.E.; Greenwood, J.R. Introduction to Ecotechnological Solutions; Springer: Dordrecht, The Netherlands, 2008; pp. 1-8.

29. Hales, T.C.; Ford, C.R.; Hwang, T.; Vose, J.M.; Band, L.E. Topographic and ecologic controls on root reinforcement. J. Geophys. Res. Earth Surf. 2009, 114. [CrossRef]

30. Schwarz, M.; Lehmann, P.; Or, D. Quantifying lateral root reinforcement in steep slopes-from a bundle of roots to tree stands. Earth Surf. Process. Landf. 2010, 35, 354-367. [CrossRef] 
31. Mao, Z.; Saint-André, L.; Genet, M.; Mine, F.-X.; Jourdan, C.; Rey, H.; Courbaud, B.; Stokes, A. Engineering ecological protection against landslides in diverse mountain forests: Choosing cohesion models. Ecol. Eng. 2012, 45, 55-69. [CrossRef]

32. Bhom, W. Methods of Studying Root Systems; Springer: Berlin, Germany, 1979.

33. Wang, S.; Zeng, R.; Qiao, L.; Meng, X.; Wangle, X.; Cui, Z. Root distribution and tensile strength of Robinia pseudoacacia Linn. on debris slopes. J. Lanzhou Univ. (Nat. Sci.) 2014, 50, 18. (In Chinese)

34. Schwarz, M.; Giadrossich, F.; Cohen, D. Modeling root reinforcement using root-failure Weibull survival function. Hydrol. Earth Syst. Sci. Discuss. 2013, 10, 3843-3868. [CrossRef]

35. Nguyen, T.S.; Likitlersuang, S.; Jotisankasa, A. Influence of the spatial variability of the root cohesion on a slope-scale stability model: A case study of residual soil slope in Thailand. Bull. Eng Geol Environ. 2019, 78, 3337-3351. [CrossRef]

36. Genet, M.; Kokutse, N.; Stokes, A.; Fourcaud, T.; Cai, X.; Ji, J.; Mickovski, S. Root reinforcement in plantations of Cryptomeria japonica D. Don: Effect of tree age and stand structure on slope stability. For. Ecol. Manag. 2008, 256, 1517-1526. [CrossRef]

37. Bischetti, G.B.; Chiaradia, E.A.; Simonato, T.; Speziali, B.; Vitali, B.; Vullo, P.; Zocco, A. Root strength and root area ratio of forest species in Lombardy (Northern Italy). Plant Soil 2005, 278, 11-22. [CrossRef]

38. Nilaweera, N.S.; Nutalaya, P. Role of tree roots in slope stabilisation. Bull. Eng Geol Environ. 1999, 57, $337-342$. [CrossRef]

39. Lin, Z. Geotechnical Engineering Test Manual; China Architecture \& Building Press: Beijing, China, 2005.

40. Schwarz, M.; Preti, F.; Giadrossich, F.; Lehmann, P.; Or, D. Quantifying the role of vegetation in slope stability: A case study in Tuscany (Italy). Ecol. Eng. 2010, 36, 285-291. [CrossRef]

41. Chirico, G.B.; Borga, M.; Tarolli, P.; Rigon, R.; Preti, F. Role of Vegetation on Slope Stability under Transient Unsaturated Conditions. Procedia Environ. Sci. 2013, 19, 932-941. [CrossRef]

42. Greenwood, J.R.; Norris, J.; Wint, J. Assessing the contribution of vegetation to slope stability. Proc. Inst. Civ. Eng. Geotech. Eng. 2004, 157, 199-207. [CrossRef]

43. Ennos, A. The mechanics of root anchorage. Adv. Bot. Res. 2000, 33, 133-157.

44. Carson, M.A.; Kirkby, M.J. Hillslope Form and Process; Cambridge University Press: Cambridge, UK, 1972.

45. Fellenius, W. Erdstatishe Berechmungen Mit Reibungund Cohesion; Ernest Verlag: Berlim, Germany, 1927.

46. Bishop, A.W. The use of the slip circle in the stability analysis of slopes. In The Essence of Geotechnical Engineering: 60 Years of Géotechnique; Thomas Telford Publishing: London, UK, 2008; pp. 223-233.

47. Janbu, N.; Bjerrum, L.; Kjaernsli, B. Soil Mechanics Applied to Some Engineering Problems; Norwegian Geotechnical Institute: Olso, Norway, 1956.

48. Morgenstern, N.; Price, V. A numerical method for solving the equations of stability of general slip surfaces. Comput. J. 1967, 9, 388-393. [CrossRef]

49. Konôpka, B.; Noguchi, K.; Sakata, T.; Takahashi, M.; Konôpková, Z. Fine root dynamics in a Japanese cedar (Cryptomeria japonica) plantation throughout the growing season. For. Ecol. Manag. 2006, 225, 278-286. [CrossRef]

50. Danjon, F.; Khuder, H.; Stokes, A. Deep Phenotyping of Coarse Root Architecture in R. pseudoacacia Reveals That Tree Root System Plasticity Is Confined within Its Architectural Model. PLoS ONE 2013, 8, e83548. [CrossRef]

51. Genet, M.; Stokes, A.; Salin, F.; Mickovski, S.B.; Fourcaud, T.; Dumail, J.-F.; Van Beek, R. The Influence of Cellulose Content on Tensile Strength in Tree Roots. Plant Soil 2005, 278, 1-9. [CrossRef]

(C) 2020 by the authors. Licensee MDPI, Basel, Switzerland. This article is an open access article distributed under the terms and conditions of the Creative Commons Attribution (CC BY) license (http://creativecommons.org/licenses/by/4.0/). 